\title{
Level up the life!! Leisure Involvement, Basic Psychological Need Satisfaction and Life Satisfaction among University Students
}

\author{
Feyza Meryem Kara ${ }^{1} \&$ Halil Sarol $^{1}$ \\ ${ }^{1}$ Kırıkkale University, Turkey \\ Correspondence: Feyza Meryem Kara, Kırıkkale University, Turkey. Tel: 90-507-232-2185. E-mail: \\ feyzameryemkara@gmail.com
}

Received: October 6, 2021

Accepted: October 28, $2021 \quad$ Online Published: November 7, 2021

doi:10.5539/hes.v11n4p91

URL: https://doi.org/10.5539/hes.v11n4p91

\begin{abstract}
Leisure participation, life satisfaction, and psychological needs stand out as concepts that are closely related to each other especially in exercise participation. The purpose of this study is to determine and analyze leisure involvement, basic psychological need satisfaction, and life satisfaction level concerning some variables among university students who are regular exercise participants. Study participants comprised a total of 428 university students who were regular exercise participants. The participants, who were chosen using a convenience sampling method, completed the "Modified Involvement Scale" (MIS), "Basic Psychological Needs in Exercise Scale" (BPNES) and Life Satisfaction Scale" (LSS). T-test, MANOVA, and correlation analysis were used to analyze the data. Results indicated that the main effect of gender was significant on "MIS" "BPNES" and "LSS" in favor of male participants. There were significant effects of type of exercise in favor of individual exercise participants. Further, there were statistically significant correlations between all scales. Participation in leisure activities positively affects the person's perspectives on all areas of life and determines the individual's feelings like autonomy, competency, and feeling more related to their lives. The findings of this study also give useful insights into exercise psychology research and provide suggestions for future research.
\end{abstract}

Keywords: autonomy, competence, connection, life satisfaction

\section{Introduction}

Positive psychology studies are defined as a discipline researching which factors affect the quality of life, and how and why they are effective in a general approach (Compton, 2019). At this point, it can be said that positive psychological approaches areas of life and outputs from a 'preventive' viewpoint. Research about positive psychology is rapidly increasing, and it appears concepts like psychological resilience, subjective well-being, life satisfaction, and interpersonal relationships are investigated (Seligman \& Csikszentmihalyi, 2014). It can be said that research topics in positive psychology create interdisciplinary research. At this point, it appears that in recent years, leisure researchers have focused on topics like motivation, satisfaction, and involvement (Stebbins, 2016).

Leisure involvement describes meaning like the appeal of activity for individuals, the importance of activity, self-expression within an activity, forming social relationships through activity, and identification with activity (Chien, 2020; Havitz \& Dimanche, 1999). At this point, where and how the motivation forms (from internal or external motivation sources) appears to be important in terms of the sustainability of the activity. Additionally, ensuring integration in a psychological context may affect concepts like spatial commitment and attitude to change. This situation brings psychological integration or commitment and basic psychological needs to the agenda. At the same time, psychological commitment emerging with involvement affects the status of being a loyal participant in activity (Chen et al., 2013). For this reason, the topic of 'need' should be investigated at the point of being loyal to this commitment and/or activity.

Humans have some requirements that they expect to be fulfilled; the aim of satisfying these needs lies at the heart of people's participation in activities (Vallerand et al., 2007). Basic psychological needs encompass topics like the individual taking their actions, being able to choose actions, hoping to affect their surroundings well and the need of individuals to connect with others. At this point, it is possible to mention concepts like the importance of subjective values of individuals and life satisfaction (Qian et al., 2020; Vansteenkiste et al., 2020).

Life satisfaction is defined as an individual's general judgments and assessment about the life they have (Diener 
et al., 1985). The individual's comparison of their situation with situations with appropriate standards plays a role in the formation of life satisfaction judgments carrying subjective qualities (Zhang et al., 2020). One of the most important periods when individuals internalize leisure habits, define psychological needs, and begin to reflect and understand perceptions and assessments about life appears to be the university years. During university, young people prepare for working life, try out adult roles, acquire more values related to life, and additionally, it encompasses a period when the games played, and leisure experiences are lived and shaped independently. In this period, the perspective on the life of young people should be given importance and value. For example, young people in this period appear to attach more importance to life satisfaction and happiness rather than money, recognize leisure areas and perceive basic needs (De Looze et al., 2018; Gürbüz \& Henderson, 2013; Tan \& Jetzke, 2020). In this context, investigation of leisure involvement, basic psychological needs, and life satisfaction topics together in the university student sample are very important. From the perspective of professionals and researchers, the question of how individuals perceive the 'best' experience in leisure activities is important. Determining the degree of effect of leisure activities, because of basic psychological needs, on life satisfaction may assist professionals and researchers in the development of strategies resulting in satisfied individuals.

\subsection{Leisure Involvement}

The topic of leisure involvement has been the mainstream in contemporary research since the 1980s and is the topic of much research (Cheng et al., 2016; Wu et al., 2020). When the definitions in research are examined, leisure participation represents an individual's emotional participation in certain leisure activities, environments, relevant facilities, and products ( $\mathrm{Li}$ et al., 2020). Additionally, leisure activities may reflect the importance and enjoyment of individuals and individual areas of life and may be defined as a way of explaining or displaying oneself to the external world (Havitz \& Dimanche, 1999). When research about leisure involvement was investigated, it appears that the focus was defining the leisure involvement construct. There is a consensus about the conceptualization of leisure involvement as a multidimensional construct (Kyle, G., \& Chick, 2002). Moving from this point, this consensus involves topics like appeal, importance, self-expression, social relationships, and identification (Kyle, G., \& Chick, 2002; Yoon et al., 2020; Xie, et al., 2020).

The first stage in leisure experience is the "attractiveness " subdimension meaning an activity that is enjoyable, entertaining, and interesting for an individual. At this point, for an activity to be appealing, the perception of it as being exciting, interesting, and entertaining plays an important role in encouraging participation (Li et al., 2020). Additionally, attractiveness appears to be an important point from a strategic aspect in marketing. For this reason, this is a topic assessed from the perspective of a business approach. In terms of businesses, the personal value of activity for a person and how important participation is to them affects appeal and is assessed as another aspect ensuring continuity of participation (Xie, et al., 2020). Additionally, the "centrality" dimension, representing the perceived place and importance of activity in the life of the individual, is associated with daily life and social structure (Chien,2020). Stated more clearly, for individuals, the activity involves meanings like relaxation, positive health outcomes, development of skills, and forming social relationships (Cheng et al., 2016). Another subdimension of "identity affirmation" is the presentation of the desired self of individuals to others and the external world communicated through activities chosen, in the most general definition. At this point, activity carries representative power for an individual and expresses symbolic value. Individuals may experience identification (internal motivation) through the activity, along with situations representing their identity to those around them (external motivation) ( $\mathrm{Li}$ et al., 2020; Xie et al., 2020). The "social bonding" subdimension represents forming relationships with society through participation in activities; in short, meaning socialization. At this point, ensuring associations with a variety of social structures which increase leisure involvement appears to be an important point (Seligman \& Csikszentmihalyi, 2014). The final construct in leisure involvement appears to be the "identity expression" subdimension. This subdimension representing the mutual bond between the activity and individual is defined as satisfying the needs of the individual through identification (Havitz \& Dimanche, 1999; Johnson et al., 2006).

\subsection{Basic Psychological Need Satisfaction}

People's basic needs have been a topic of research for a very long time (Vansteenkiste et al., 2020). People act in line with their needs and the motivation to fulfill certain needs is at the basis of these behaviors (Qian, 2020). The self-determination theory of Ryan and Deci proposes that people have psychological well-being levels to the degree to which these needs are satisfied (Ryan \& Deci, 2020). According to the self-determination concept, people have some needs that they expect to be satisfied and the basis of people's participation in activities is to fulfill these needs (Vallerand et al., 2007). The self-determination concept is a motivation concept attempting to explain behavior displayed according to the motivation levels of people (Wilson \& Rodgers, 2002). Additionally, 
the concept states that people participate in exercise they choose themselves and gain satisfaction from the exercise activities they participate in. Motivation in the self-determination concept is closely associated with the individual's ability to act according to their own free will (Ryan \& Deci, 2020; Wilson \& Rodgers, 2002). For this reason, the self-determination concept is an important determinant, not just at the point of participating in exercise, but also about participation in leisure activities (Vallerand et al., 2007).

Mini theories are emerging from the self-determination concept. The first of these is the cognitive assessment theory bringing the effects of social elements on internal motivation to the forefront. The second is the organismic internalization theory bringing the internalization concept, especially the development of external motivation, to the forefront. Additionally, causality orientations theory emphasizes individual differences about free will behavior and orientation toward surroundings in a way that will support people's free will. Finally, basic psychological needs theory deals with basic needs and investigates the effect of this concept on psychological well-being and psychological health (Vasconcellos et al., 2020). The self-determination concept emerges from the combination of these theories.

According to self-determination theory, people have three basic psychological needs. These are called autonomy, competence, and connection (Ryan \& Deci, 2020; Wilson \& Rodgers, 2002). The first of these needs of "autonomy" represents a person's chance of choosing activities in their lives. This means a person's ability to determine their behavior and to decide independently. This need is met by the degree to which people have the chance to choose. The second need is competence, and this is the state of being "competent" emerging from the personal ability to utilize their capacity. This need is thought to be met in people who can successfully achieve the tasks they perform and who are aware of competence due to being praised for their work. The third and final need is "relatedness" and represents the feeling of connection when people interact with others. People need to belong, and connection will increase to the degree to which people feel they belong to some other people or groups (Benita, 2020; Ryan \& Deci, 2020; Wilson \& Rodgers, 2002; Vasconcellos et al., 2020).

According to the self-determination concept, people have some cognitive processes which regulate behavior oriented toward fulfilling the needs mentioned above. In other words, there is a different cognitive form underlying every behavior displayed according to the self-determination concept. These cognitive forms are divided in two as internal and external patterns. External patterns emerge linked to the individual's behavior being displayed linked to an external condition or need. Internal patterns emerge when the behavior displayed in an individual is not linked to any external element (Ingledew et al., 2004). Additionally, the self-determination theory proposes the view that external factors affect internal motivation from some aspects. According to the theory, people with low motivational levels for exercise experience motivation loss. People with motivation loss enter a tendency to feel they are unskilled at the activity and cannot control their expectations. Additionally, the low internal and external motivation of an individual can prepare the way for engaging in activities aimlessly (Ingledew et al., 2004; Ryan \& Deci, 2020).

\subsection{Life Satisfaction}

Much research has been researched about cognitive assessment of a person's own life in recent years (Yoon et al., 2020). Moving from this point, the life satisfaction concept appears to come to the agenda frequently. Life satisfaction is a positive assessment of life by certain criteria the individual determines for themselves (Diener et al., 1985). Life satisfaction is a holistic assessment related to how good an individual's life is about their criteria, qualified in areas like family, friends, and school (Idárraga-Cabrera et al., 2020). The individual's life satisfaction judgment is linked to their subjective criteria and does not reflect externalized conditions; for this reason, it is labeled as subjective (Vasconcellos, 2020). It encompasses the person's satisfaction yesterday, today, and tomorrow, desire to change their lives, and opinions of those close to them about that person's life (Diener \& Lucas, 1999). Life satisfaction, representing cognitive aspects of concepts related to an individual's happiness (Diener et al., 1985), encompasses satisfaction in the past and future along with present life, and the desire to change their life and includes family, leisure, health, and work-life Diener et al., 2002). Additionally, it may be assessed as a reliable measure of the quality of life encompassing physical, mental, and social welfare (Diener et al., 2002; Yoon et al., 2020).

For this reason, life satisfaction with different definitions is indicated to have six different components (income, occupation, and social status, opportunities and social mobility, welfare provisions, government policies/environment, and family/social connections (Appleton \& Song, 2008). Additionally, Akbar et al. (2014) stated there were five elements of life satisfaction of (1) culture, (2) work, (3) education, (4) age, and (5) social relations. At this point, the definitions, life satisfaction of individuals can be said to be affected by happiness in daily life, meaning given to life, compatibility in terms of achieving aims, positive personal identity, the 
individual feeling physically well, economic security, and social relations (Appleton \& Song, 2008; Pavot \& Diener, 2008).

There are many conceptual approaches related to the life satisfaction concept. According to the top-down/bottom-up theory, happy life is formed by a collection of happy moments and people achieving satisfaction are happy (Kozma \& Stones, 1980). Additionally, according to the telic theory, satisfied needs of individuals lead to happiness, while unsatisfied needs lead to unhappiness (Wilson, 1961). According to activity theory, happiness is proposed to develop because of virtuous activities (social activities like sports, hobbies, travel) (Csikszentmihalyi \& Figurski, 1982). According to the associationistic theory, the cognitive factor is accepted as a determinant of satisfaction and this concept focuses on the importance of meaning given to events by individuals. It is considered that cognitive conditioning may affect happiness or unhappiness (Schwartz \& Clore, 1983). Finally, according to the judgment theory, individuals compare their present situation with standards they consider as criteria and obtain or don't obtain satisfaction from life. Depending on how compatible these situations are, the higher the life satisfaction. The society in which a person lives, their abilities, feelings, life experience, and life events will affect this satisfaction (Chang, 2017). As can be seen, there is a virtual plethora of measurement approaches and accompanying theoretical perspectives. In this paper, the focus will be on activity theory-based conceptualizations and measurement of the life satisfaction construct.

\section{Method}

\subsection{Participants}

The participants, consist of 428 university students who were chosen using a convenience sampling method and exercise participants attending different sport centres in Ankara, Turkey ( $\mathrm{n}=214$ females and $\mathrm{n}=214$ males). Participants ranged in age from 18 to 23 years $(\mathrm{M}=22.12, \mathrm{SD}=0.92)$. The participants reported they represented various exercise class and groups (fitness, yoga, pilates, swimming, crossfit, Zumba, kickboxing, kangoo-jumps, aerobics, tae-bo, and aqua aerobics). The participants had approximately five years of exercise experience (M $=4,57 ; \mathrm{SD}=1.12$ years).

\subsection{Sampling Procedures}

Respondents were systematically intercepted by researchers (every second person) in the reception areas of health clubs during mornings, afternoons, and evenings on both weekdays and weekends, seven days a week. The questionnaires were completed before their exercise session. On average, it took respondents approximately 15 minutes to complete the survey instrument. Verbal and visual information were provided about how to respond to items in each questionnaire.

\subsection{Data Collection Tool}

Personal Information Form: Demographic data (age, gender, and type of exercise) of the participants were collected with a personal information form developed by the researchers.

Modified Involvement Scale (MIS) (Kyle et al., 2007) was used to assess levels of enduring involvement among exercise participants. The MIS comprises 15 items. Responses are provided on a five-point Likert-type scale ranging from 1 ('Strongly disagree') to 5 ('Strongly agree'). In this study, the internal consistency coefficients for the MIS subscales were 0.84 for attraction, 0.87 for centrality, 0.91 for social bonding, 0.83 for identity affirmation, and 0.91 for identity expression.

Basic Psychological Needs in Exercise Scale (BPNES) (Vlachopoulos \& Michailidou, 2006) is a self-report measure designed to assess the extent to which the innate psychological needs for autonomy, competence, and relatedness are fulfilled by exercise. It comprises 12 items, divided into three subscales with 4 items per subscale. Higher scores demonstrate that participants consider their needs to be more fulfilled. In this study, the internal consistency coefficients for the BPNES subscales were 0.82 for autonomy, 0.83 for competence, and 0.91 for relatedness.

Life Satisfaction Scale (LSS) (Diener et al., 1985) is a 5-item scale designed to measure global cognitive judgments of one's life satisfaction (not a measure of either positive or negative affect). Participants indicate how much they agree or disagree with each of the 5 items using a 7-point scale that ranges from 7 strongly agree to 1 strongly disagree. Higher scores demonstrate that participants consider they are more satisfied with life. In this study, the internal consistency coefficient for the LSS total score was 0.82 .

\subsection{Analysis of Data}

The participants were informed about the confidentiality of personal information during the data collection process. University students were informed that completion of the inventory was voluntary. collected data were 
analyzed with SPSS 23.00. T-test MANOVA, ANOVA and Correlation Analysis were used in this study. Additionally, students t-test and MANOVA was used to determine internet addiction, perceived freedom in leisure, leisure boredom, sensation seeking according to gender and physical activity participation. Correlation Analysis was used to investigate the relationship between internet addiction, perceived freedom in leisure, leisure boredom and sensation seeking of the university students.

\section{Results}

The MANOVA results showed that the basic effect of the gender variable in MIS was significant $(\mathrm{p}<0.01)$ (Hotelling's: $\left.0.00, \mathrm{~F}_{(1.395)}=5.770, \mathrm{p}<0.01\right)$. When the attraction sub-dimension was evaluated, a significant difference was determined in favor of male participants $\mathrm{F}_{(1.395)}=3.127$; $\left.\mathrm{p}<0.05\right)$.

According to the MANOVA results, the main effect of participation on the gender variable was determined to be significant $(\mathrm{p}<0.01)$ in BPNS (Hotelling's: 0.00, $\mathrm{F}_{(1.395)}=5.704$, $\mathrm{p}<0.01$ ). When the autonomy $\mathrm{F}_{(1.395)}=3.127$; $\mathrm{p}<0.05)$ and competence $\left.\mathrm{F}_{(1.395)}=3.127 ; \mathrm{p}<0.05\right)$ sub-dimensions were evaluated, a significant difference was determined in favor of male participants.

According to $\mathrm{t}$-test results, the average points of participants from LSS $\left(\mathrm{t}_{(397)}=0.906 ; \mathrm{p}<0.05\right)$ varied significantly according to the gender variable. According to the findings, a significant difference was found in favor of male participants.

Table 1. MANOVA (MIS and BPNS) and t-test (LSS) Results of Exercise Participants According to Gender

\begin{tabular}{lllllll}
\hline & & & $\mathbf{N}$ & $\mathbf{X}$ & $\mathbf{S d}$ & $\mathbf{p}$ \\
\hline Modified Leisure & Attraction & Female & 124 & 3.07 & .92 & .000 \\
Involvement Scale & \multirow{2}{*}{ Centrality } & Male & 124 & 3.55 & 1.07 & \\
& & Female & 124 & 2.69 & .96 & .166 \\
& Social Bonding & Male & 124 & 2.88 & 1.10 & \\
& & Female & 124 & 3.12 & .98 & .311 \\
& Identity affirmation & Male & 124 & 3.25 & .97 & \\
& & Female & 124 & 3.12 & 1.07 & .736 \\
& \multirow{2}{*}{ Identity expression } & Male & 124 & 3.17 & 1.05 & \\
& & Female & 124 & 3.10 & .96 & .282 \\
Basic Psychological Need & \multirow{2}{*}{ Autonomy } & Male & 124 & 3.23 & 1.00 & \\
Satisfaction Scale & & Female & 124 & 3.67 & .78 & .001 \\
& \multirow{2}{*}{ Competence } & Male & 124 & 3.97 & .65 & \\
& & Female & 124 & 3.40 & .91 & .005 \\
& \multirow{2}{*}{ Relatedness } & Male & 124 & 3.70 & .77 & \\
& & Female & 124 & 3.79 & .73 & .068 \\
Life Satisfaction Scale & & Male & 124 & 3.95 & .65 & \\
& & Female & 124 & 4.68 & 1.06 & .009 \\
\hline & & Male & 124 & 5.03 & .97 & \\
\hline
\end{tabular}

The MANOVA results showed that the basic effect of the exercise type variable in LIS was significant $(\mathrm{p}<0.01)$ (Hotellings: $\left.0.00, \mathrm{~F}_{(1.395)}=5.770, \mathrm{p}<0.01\right)$. When all the LIS sub-dimensions are evaluated, a significant difference was determined in favor of individual exercise participants $F_{(1.395)}=3.127 ; p<0.05 ; F_{(1.395)}=3.127 ; p<0.05$; $\left.\mathrm{F}_{(1.395)}=3.127 ; \mathrm{p}<0.05 ; \mathrm{F}_{(1.395)}=3.127 ; \mathrm{p}<0.05 ; \mathrm{F}_{(1.395)}=3.127 ; \mathrm{p}<0.05\right)$.

According to the MANOVA results, the main effect of participation on the exercise type variable was not determined to be significant on BPNS ( $p>0.01$ ) (Hotelling's: 0.00, $\mathrm{F}_{(1.395)}=5.704, \mathrm{p}<0.01$ ).

According to Table 2, no statistically significant difference was found in LIS total score regarding exercise type $(\mathrm{p}>0.05)\left(\mathrm{t}_{(397)}=0.906 ; \mathrm{p}>0.05\right)$. 
Table 2. MANOVA (MIS and BPNS) and t-test (LSS) Results for Exercise Participants According to Type of Exercise

\begin{tabular}{lllllll}
\hline & & & $\mathrm{N}$ & $\mathrm{X}$ & $\mathrm{Sd}$. & $\mathrm{P}$ \\
\hline Modified Leisure & Attraction & Group & 137 & 3.03 & 1.01 & .000 \\
Involvement Scale & & Individual & 111 & 3.65 & .94 & \\
& Centrality & Group & 137 & 2.57 & .99 & .000 \\
& & Individual & 111 & 3.06 & 1.03 & \\
& \multirow{2}{*}{ Social Bonding } & Group & 137 & 3.00 & .98 & .001 \\
& & Individual & 111 & 3.41 & .93 & \\
& \multirow{2}{*}{ Identity affirmation } & Group & 137 & 2.92 & 1.06 & .000 \\
& & Individual & 111 & 3.43 & .99 & \\
& \multirow{2}{*}{ Identity expression } & Group & 137 & 2.99 & 1.00 & .002 \\
& & Individual & 111 & 3.38 & .91 & \\
Basic Psychological & \multirow{2}{*}{ Autonomy } & Group & 137 & 3.80 & .82 & .580 \\
& & Individual & 111 & 3.85 & .62 & \\
& \multirow{2}{*}{ Competence } & Group & 137 & 3.58 & .96 & .502 \\
& & Individual & 111 & 3.51 & .71 & \\
& \multirow{2}{*}{ Relatedness } & Group & 137 & 3.84 & .80 & .368 \\
& & Individual & 111 & 3.92 & .54 & \\
Life Satisfaction Scale & & Group & 137 & 4.86 & 1.00 & .880 \\
& & Individual & 111 & 4.84 & 1.00 & \\
\hline
\end{tabular}

As a result of correlation analysis, it was determined that there were positive relationships between all sub-dimensions of "MIS", "BPNS" and mean scores of "LSS", except for life satisfaction total scores, between centrality, relatedness, and identity affirmation sub-dimensions ( $p>0.05$; Table 3 ).

Table 2. Correlation Analysis Results for LIS, BPNS and LIS

\begin{tabular}{|c|c|c|c|c|c|c|c|c|c|}
\hline & 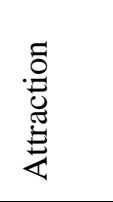 & 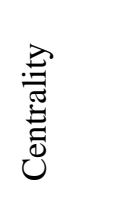 & 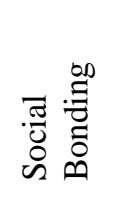 & 胥莺 & 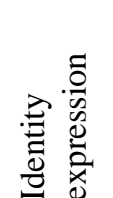 & 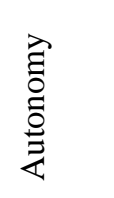 & 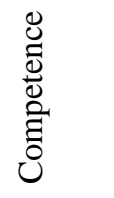 & 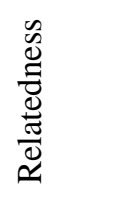 & 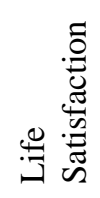 \\
\hline Attraction & 1 & & & & & & & & \\
\hline Centrality & $.700 * *$ & 1 & & & & & & & \\
\hline Social Bonding & $.591 * *$ & $.564 * *$ & 1 & & & & & & \\
\hline Identity affirmation & $.707 * *$ & $.719 * *$ & $.707 * *$ & 1 & & & & & \\
\hline Identity expression & $.430 * *$ & $.523 * *$ & $.567 * *$ & $.649 * *$ & 1 & & & & \\
\hline Autonomy & $.451 * *$ & $.250 * *$ & $.408 * *$ & $.374 * *$ & $.274 * *$ & 1 & & & \\
\hline Competence & $.342 * *$ & $.207 * *$ & $.438 * *$ & $.283 * *$ & $.242 * *$ & $.585 * *$ & 1 & & \\
\hline Relatedness & $.411^{* *}$ & $.223^{* *}$ & $.385 * *$ & .374 & $.281 * *$ & $.799 * *$ & $.547 * *$ & 1 & \\
\hline Life Satisfaction & $.145^{*}$ & -.003 & $.173 * *$ & .110 & $.130 *$ & $.548 * *$ & $.224 * *$ & $.352 * *$ & 1 \\
\hline
\end{tabular}

\section{Discussion}

This study aimed to examine leisure involvement, basic psychological need satisfaction, and life satisfaction level concerning some variables for university students who are regular exercise participants, and to investigate the relationship between leisure involvement, basic psychological need satisfaction, and life satisfaction.

Considering theoretical and empirical studies related to leisure involvement up to the 2000s, it is very surprising the topic of gender received very little interest or no attention at all (Wiley et al., 2000). When leisure involvement studies researching gender differences in recent years are examined, again, it appears male-dominant results were obtained (Chang, 2017; Wiley et al., 2000). According to the research results, the gender variable was found to have a significant difference in favor of male participants for the "attraction" subdimension of "MIS". Compared to female participants, male participants can be said to perceive their activities as more exciting, interesting, and entertaining.

Individuals may tend to participate in similar activities for different reasons in certain periods of life. Many 
factors may be discussed within the framework of these periods. However, the gender topic is beyond these. Due to some physical activities creating more masculine connotations and to social gender attitudes about this topic, they may be said to be chosen more by men. As a result, these results may be outcomes of the patriarchal and hegemonic view, like "masculine" and "feminine" sports.

Another topic related to leisure involvement is the form of participation in activities. Van Ingen and Van Eijck (2009) stated that individuals who participate in leisure activities with friends outside of family have more advantages from a social view than those who participate alone. Participation in recreational physical activities in groups in a variety of spaces offers benefits to individuals from a variety of aspects; for this reason, this situation is proposed to increase motivation and interest levels among individuals for these activities (Sarol \& Çimen, 2017, Valeri et al., 2013). According to research findings within this scope, there were significant differences for the exercise type variable in favor of individual exercise participants for all "MIS" subdimensions. According to individuals participating in activities alone, leisure activities may be qualified as being more exciting, interesting, entertaining, and having more personal value ( $\mathrm{Li}$ et al., 2020). It can be concluded that participants in individual exercises like fitness and swimming are more involved than participants in group exercises such as squash, spinning, pilates, kangoo-jump, and tae-bo. Additionally, individuals participating in individual sports reflects the place and importance of the activity in their lives (Xie, 2020) and is even a form of self-expression ( $\mathrm{Li}$ et al., 2020). Individuals who participate in activities individually can be said to be more social; in fact, they experience more identification with the activity.

Research about basic psychological needs performed within the framework of self-determination theory (SDT) focuses on gender differences in the exercise environment (Antunes et al., 2020; Vlachopoulos \& Michailidou, 2006). Much research related to exercise and sport environments are observed to obtain results in favor of male participants, showing that male participants act based on internal dynamics more than external factors and make free choices (Ghorbani et al., 2020; Hancox, 2018). Research during the recent COVID-19 pandemic did not obtain different results (Antunes et al., 2020). Similarly, according to the gender variable within the scope of this research, the BPNS "autonomy" and "competence" subdimensions were identified to have significant differences in favor of male participants. Within the framework of the research findings and relevant literature, compared to women, male participants in exercise environments appear to assess themselves as having the chance to make selections and that they evaluate these chances more (autonomy), instead of feeling they must do the activity. Additionally, men were identified to have a higher desire to have a good effect on those around them and the capacity to interact more effectively with those around them (competence need) compared to women. Additionally, it is possible to say results are in favor of men for topics like being close and connected to important people in their lives, feeling support and satisfaction in relationships, acceptance as they are by people around them, and emotional support, assistance, and trust in recommendations from surroundings (relatedness need).

Within the scope of basic psychological needs, the present research adopting the theoretical framework of SDT aimed to assess whether group participation in exercise was related to meeting basic psychological needs contrary to individual exercise participation. When research is investigated within the conceptual framework of basic psychological need dimensions (autonomy, competence, and connection), dominantly exercising in groups was shown to be associated with significantly more satisfaction of autonomy, competency, and relatedness compared to individual exercise (Lovell et al., 2016; Matosic et al., 2016). However, according to the research findings, there were no significant differences in BPNS according to exercise type. Our results are new compared to findings obtained in previous research about exercise environments with the SDT theoretical perspective (Hancox et al., 2018). The research findings can be said to show no difference for topics like choosing to participate in the exercise, effective inclusion in social environments, and support received from close relationships for individual or group exercise.

Within the scope of life satisfaction, in this study based on activity theory, a broad range of leisure activities including hobbies, cultural activities, physical exercise, and social activities were defined as a life satisfaction area (Diener et al., 1985; 2002; Pavot \& Diener, 2008]. Much research attempting to identify differences in life satisfaction has brought comparisons between genders to the forefront (Zhang et al., 2020). In this context, according to the research findings, there were significant differences for "LSS" total points in favor of male participants. There appear to be studies with similar findings to the research (Grant, Wardle and Steptoe, 2009; Moksnes and Espnes, 2013). Within the scope of research and findings, men having higher levels of life satisfaction compared to women is linked to men having more freedom and status in most cultures, while women are explained as having less power and resources in a social sense (Diener \& Seligman, 2004). Additionally, it can be said that differences in life satisfaction levels reduce in countries where there is social gender equality. In 
line with this, a study of 175,470 adolescent participants from 34 different countries identified higher life satisfaction levels for individuals living in countries with higher social gender equality (De Looze et al., 2018).

Many studies are investigating the correlation between exercise and physical activity participation with the life satisfaction concept within the scope of activity theory (Lapa, 2013; Rodríguez et al., 2008; Tan \& Jetzke, 2020). Additionally, there is no research in the literature related to life satisfaction from different exercise participation types (individual or group). According to our research findings, there were no significant differences between individual and group exercise participants for "LSS". Within the scope of the activity concept, the importance of frequency of activity and activity type are emphasized. However, the lack of assessment of activities in standard categories makes it difficult to provide specific theorization, despite the concept being frequently encountered in the literature. Currently, rather than the quantity and quality of activities, it appears the focus is on the experience of the individual during the activity and its role. For this reason, rather than the plain activity theory explaining the well-being and life satisfaction of individuals, it can be said a holistic approach is applied. Within the scope of activity theory, the process underlying the association of activity with the life satisfaction of individuals is explained by flow theory in the literature. Flow is defined as autotelic and optimal experience characterized by high levels of participation, deep concentration, internal motivation, and balance between skill levels and perceived difficulty of the activity (Csikszentmihalyi \& Figurski, 1982). The experience of flow increases life satisfaction by changing a person's satisfaction obtained from certain activities and needs to be supported by research with experimental patterns (Chen et al., 2013). As a result, the research findings are in the situation of partly providing this support.

For the other topics in the research hypotheses, the correlations between variables should be researched. As a result of correlation analysis, it was determined that there were positive relationships between all sub-dimensions of "MIS “, "BPNS" and mean scores of "LSS", except life satisfaction total scores with centrality, relatedness, and identity affirmation sub-dimensions. Identification of the mediating role of psychological need satisfaction in the relationship between participation in activities and life satisfaction is known to bring different explanations about the process underlying activity theory (Leversen, 2012; Rodríguez et al., 2008). For this reason, participation in leisure activities positively affects the person's view on all areas of life and predicts the individual's feelings like autonomy, competency and feeling more connected to their lives. As a result, participants' leisure involvement increased with the increases in basic psychological need satisfaction and life satisfaction.

Some limitations of the study should be noted including the limitations of the sample, research methods, and theories and these limitations should be considered in later studies. For example, more information can be acquired from exercise participants, and exercise participation variables may be investigated in more detail. Additionally, our recommendations for research include investigation of differences between indoor and outdoor exercise participants, examination of cultural differences, and exercise experience.

\section{Acknowledgments}

This paper was presented at the Congress that was held in 2nd International Recreation and Sports Management Congress: on Bodrum/Muğla.

\section{References}

Akbar, M., Akram, M., Ahmed, M., Hussain, M. S., Lal, V., \& Ijaz, S. (2014). Relationship between resilience and life satisfaction among nomadic. International journal of innovation and applied studies, 6(3), 515.

Antunes, R., Frontini, R., Amaro, N., Salvador, R., Matos, R., Morouço, P., \& Rebelo-Gonçalves, R. (2020). Exploring lifestyle habits, physical activity, anxiety and basic psychological needs in a sample of Portuguese adults during COVID-19. International journal of environmental research and public health, 17(12), 4360. https://doi.org/10.3390/ijerph17124360

Appleton, S., \& Song, L. (2008). Life satisfaction in urban China: Components and determinants. World development, 36(11), 2325-2340. https://doi.org/10.1016/j.worlddev.2008.04.009

Benita, M. (2020). Freedom to feel: A self-determination theory account of emotion regulation. Social and personality psychology compass, 14(11), e12563. https://doi.org/10.1111/spc3.12563

Chang, H. H. (2017). Gender differences in leisure involvement and flow experience in professional extreme sport activities. World leisure journal, 59(2), 124-139. https://doi.org/10.1080/16078055.2016.1166152

Chen, Y. C., Li, R. H., \& Chen, S. H. (2013). Relationships among adolescents' leisure motivation, leisure involvement, and leisure satisfaction: A structural equation model. Social indicators research, 110(3), 
1187-1199. https://doi.org/10.1007/s11205-011-9979-2

Cheng, T. M., Hung, S. H., \& Chen, M. T. (2016). The influence of leisure involvement on flow experience during hiking activity: Using psychological commitment as a mediate variable. Asia pacific journal of tourism research, 21(1), 1-19. https://doi.org/10.1080/10941665.2014.1002507

Chien, M. K. (2020). Study on the Relationships between the Leisure Involvement, Place Attachment, and Leisure Satisfaction of Visitors Engaging in Ecotourism-A Case of Ecotourism in Southern Taiwan. American research journal of humanities \& social science, 11(3), 69-79.

Compton, W. C., \& Hoffman, E. (2019). Positive psychology: The science of happiness and flourishing. Sage Publications.

Csikszentmihalyi, M., \& Figurski, T. J. (1982). Self-awareness and aversive experience in everyday life. Journal of personality, 50(1), 15-19. https://doi.org/10.1111/j.1467-6494.1982.tb00742.x

de Looze, M. E., Huijts, T., Stevens, G. W. J. M., Torsheim, T., \& Vollebergh, W. A. (2018). The happiest kids on earth. Gender equality and adolescent life satisfaction in Europe and North America. Journal of youth and adolescence, 47(5), 1073-1085. https://doi.org/10.1007/s10964-017-0756-7

Diener, E. D., Emmons, R. A., Larsen, R. J., \& Griffin, S. (1985). The satisfaction with life scale. Journal of personality assessment, 49(1), 71-75. https://doi.org/10.1207/s15327752jpa4901_13

Diener, E., \& Lucas, R. E. (1999). Personality and subjective well-being. Well-being: Foundations of hedonic psychology, 213.

Diener, E., \& Seligman, M. E. (2004). Beyond money: Toward an economy of well-being. Psychological science in the public interest, 5(1), 1-31. https://doi.org/10.1111/j.0963-7214.2004.00501001.x

Diener, E., Lucas, R. E., \& Oishi, S. (2002). Subjective well-being: The science of happiness and life satisfaction. Handbook of positive psychology, 2, 63-73.

Fraguela-Vale, R., Varela-Garrote, L., Carretero-García, M., \& Peralbo-Rubio, E. M. (2020). Basic psychological needs, physical self-concept, and physical activity among adolescents: Autonomy in focus. Frontiers in psychology, 11, 491. https://doi.org/10.3389/fpsyg.2020.00491

Ghorbani, S., Nouhpisheh, S., \& Shakki, M. (2020). Gender Differences in the Relationship between Perceived Competence and Physical Activity in Middle School Students: Mediating Role of Enjoyment. International journal of school health, 7(2), 14-20. https://doi.org/10.30476/intjsh.2020.85668.1056

Grant, N., Wardle, J., \& Steptoe, A. (2009). The relationship between life satisfaction and health behavior: a cross-cultural analysis of young adults. International journal of behavioral medicine, 16(3), 259-268. https://doi.org/10.1007/s12529-009-9032-x

Gürbüz, B., \& Henderson, K. (2013). Exploring the meanings of leisure among Turkish university students. Croatian journal of education: Hrvatski časopis za odgoj i obrazovanje, 15(4), 927-957.

Hancox, J. E., Quested, E., Ntoumanis, N., \& Thøgersen-Ntoumani, C. (2018). Putting self-determination theory into practice: Application of adaptive motivational principles in the exercise domain. Qualitative research in sport, exercise and health, 10(1), 75-91. https://doi.org/10.1080/2159676X.2017.1354059

Havitz, M. E., \& Dimanche, F. (1999). Leisure involvement revisited: Drive properties and paradoxes. Journal of leisure research, 31(2), 122-149. https://doi.org/10.1080/00222216.1999.11949854

Idárraga-Cabrera, C., Dueñas, J. M., Martínez-González, M. B., Navarro-Blanco, R., Denegri-Coria, M., \& Pino, M. (2020). Cognitive Functioning, Life Satisfaction, and Their Relationship with the Financial Attitudes of Older Individuals Who Participate in an Active Aging Program. Behavioral sciences, 10(12), 189. https://doi.org/10.3390/bs10120189

Ingledew, D. K., Markland, D., \& Sheppard, K. E. (2004). Personality and self-determination of exercise behaviour. Personality and individual differences, 36(8), 1921-1932. https://doi.org/10.1016/j.paid.2003.08.021

Johnson, H. A., Zabriskie, R. B., \& Hill, B. (2006). The contribution of couple leisure involvement, leisure time, and leisure satisfaction to marital satisfaction. Marriage \& family review, 40(1), 69-91. https://doi.org/10.1300/J002v40n01_05

Kozma, A., \& Stones, M. J. (1980). The measurement of happiness: Development of the Memorial University of Newfoundland Scale of Happiness (MUNSH). Journal of gerontology, 35(6), 906-912. 
https://doi.org/10.1093/geronj/35.6.906

Kyle, G., \& Chick, G. (2002). The social nature of leisure involvement. Journal of leisure research, 34(4), 426-448. https://doi.org/10.1080/00222216.2002.11949980

Kyle, G., Absher, J., Norman, W., Hammitt, W., \& Jodice, L. (2007). A modified involvement scale. Leisure studies, 26(4), 399-427. https://doi.org/10.1080/02614360600896668

Lapa, T. Y. (2013). Life satisfaction, leisure satisfaction and perceived freedom of park recreation participants. Procedia-social and behavioral sciences, 93, 1985-1993. https://doi.org/10.1016/j.sbspro.2013.10.153

Leversen, I., Danielsen, A. G., Birkeland, M. S., \& Samdal, O. (2012). Basic psychological need satisfaction in leisure activities and adolescents' life satisfaction. Journal of youth and adolescence, 41(12), 1588-1599. https://doi.org/10.1007/s10964-012-9776-5

Li, Z., Ge, Y., Su, Z., \& Huang, X. (2020). Audience leisure involvement, satisfaction and behavior intention at the Macau Science Center. The electronic library, 38(2), 383-401. https://doi.org/10.1108/EL-07-2019-0176

Lovell, G. P., Gordon, J. A., Mueller, M. B., Mulgrew, K., \& Sharman, R. (2016). Satisfaction of basic psychological needs, self-determined exercise motivation, and psychological well-being in mothers exercising in group-based versus individual-based contexts. Health care for women international, 37(5), 568-582. https://doi.org/10.1080/07399332.2015.1078333

Matosic, D., Ntoumanis, N., \& Quested, E. (2016). Antecedents of need supportive and controlling interpersonal styles from a self-determination theory perspective: A review and implications for sport psychology research. Sport and exercise psychology research, 145-180. https://doi.org/10.1016/B978-0-12-803634-1.00007-8

Moksnes, U. K., \& Espnes, G. A. (2013). Self-esteem and life satisfaction in adolescents-gender and age as potential moderators. Quality of life research, 22(10), 2921-2928. https://doi.org/10.1007/s11136-013-0427-4

Pavot, W., \& Diener, E. (2008). The satisfaction with life scale and the emerging construct of life satisfaction. The journal of positive psychology, 3(2), 137-152. https://doi.org/10.1080/17439760701756946

Peterson, C., Park, N., \& Seligman, M. E. (2005). Orientations to happiness and life satisfaction: The full life versus the empty life. Journal of happiness studies, 6(1), 25-41. https://doi.org/10.1007/s10902-004-1278-Z

Qian, T. Y., Wang, J. J., Zhang, J. J., \& Hulland, J. (2020). Fulfilling the Basic Psychological Needs of Esports Fans: A Self-Determination Theory Approach. Communication \& sport, 2167479520943875. https://doi.org/10.1177/2167479520943875

Rodríguez, A., Látková, P., \& Sun, Y. Y. (2008). The relationship between leisure and life satisfaction: Application of activity and need theory. Social indicators research, 86(1), 163. https://doi.org/10.1007/s11205-007-9101-y

Ryan, R. M., \& Deci, E. L. (2020). Intrinsic and extrinsic motivation from a self-determination theory perspective: Definitions, theory, practices, and future directions. Contemporary educational psychology, 61, 101860. https://doi.org/10.1016/j.cedpsych.2020.101860

Sarol, H., \& Çimen, Z. (2017). Why people participate leisure time physical activity: a Turkish perspective. Pamukkale university journal of sports sciences, 8(1), 63-72. Retrieved from https://dergipark.org.tr/en/pub/psbd/issue/34046/615255

Schwarz, N., \& Clore, G. L. (1983). Mood, misattribution, and judgments of well-being: informative and directive functions of affective states. Journal of personality and social psychology, 45(3), 513-523. https://doi.org/10.1037/0022-3514.45.3.513

Seligman, M. E., \& Csikszentmihalyi, M. (2014). Positive psychology: An introduction. Springer Netherlands. pp. 279-298. https://doi.org/10.1007/978-94-017-9088-8_18

Stebbins, R. A. (2016). Leisure and positive psychology: Linking activities with positiveness. Springer. https://doi.org/10.1007/978-1-137-56994-3

Tan, S. L., \& Jetzke, M. (2020). Is having intention good enough? The associations between stages of physical activity and life satisfaction among university students. Arne Göring/Jochen Mayer/Malte Jetzke (Hg.), 115-133.

Unanue, W., Gómez, M. E., Cortez, D., Oyanedel, J. C., \& Mendiburo-Seguel, A. (2017). Revisiting the link 
between job satisfaction and life satisfaction: The role of basic psychological needs. Frontiers in psychology, 8, 680. https://doi.org/10.3389/fpsyg.2017.00680

Valeri, B., Baez, M., \& Casati, F. (2013, September). Come Along: understanding and motivating participation to social leisure activities. In 2013 International Conference on Cloud and Green Computing. pp. 211-218. https://doi.org/10.1109/CGC.2013.41

Vallerand, R. J., Salvy, S. J., Mageau, G. A., Elliot, A. J., Denis, P. L., Grouzet, F. M., \& Blanchard, C. (2007). On the role of passion in performance. Journal of personality, 75(3), 505-534. https://doi.org/10.1111/j.1467-6494.2007.00447.x

Van Ingen, E., \& Van Eijck, K. (2009). Leisure and social capital: An analysis of types of company and activities. Leisure sciences, 31(2), 192-206. https://doi.org/10.1080/01490400802686078

Vansteenkiste, M., Ryan, R. M., \& Soenens, B. (2020). Basic psychological need theory: Advancements, critical themes, and future directions. Motivation and emotion, 44, 1-31. https://doi.org/10.1007/s11031-019-09818-1

Vasconcellos, D., Parker, P. D., Hilland, T., Cinelli, R., Owen, K. B., Kapsal, N., Lee, J., Antczak, D., Ntoumanis, N., Ryan, R. M., \& Lonsdale, C. (2020). Self-determination theory applied to physical education: A systematic review and meta-analysis. Journal of educational psychology, 112(7), 1444-1469. https://doi.org/10.1037/edu0000420

Vlachopoulos, S. P., \& Michailidou, S. (2006). Development and initial validation of a measure of autonomy, competence, and relatedness in exercise: The Basic Psychological Needs in Exercise Scale. Measurement in physical education and exercise science, 10(3), 179-201. https://doi.org/10.1207/s15327841mpee1003_4

Wiley, C. G., Shaw, S. M., \& Havitz, M. E. (2000). Men's and women's involvement in sports: An examination of the gendered aspects of leisure involvement. Leisure sciences, 22(1), 19-31. https://doi.org/10.1080/014904000272939

Wilson, P. M., \& Rodgers, W. M. (2002). The Relationship Between Exercise Motives and Physical Self-Esteem in Female Exercise Participants: An Application of Self-Determination Theory 1. Journal of applied biobehavioral research, 7(1), 30-43. https://doi.org/10.1111/j.1751-9861.2002.tb00074.x

Wilson, W. R. (1961). An attempt to determine some correlates and dimensions of hedonic tone. Dissertation Abstracts, 21, 2814.

Wu, J., Li, X., Gao, B., \& Su, X. (2020). The Effects of Serious Leisure Involvement on Subjective Well-Being and Successful Aging: A Case Study of Young-Old Participants in Chinese Seniors' Universities. SAGE open, 10(1), 2158244020914559. https://doi.org/10.1177/2158244020914559

Xie, H., Weybright, E. H., Caldwell, L. L., Wegner, L., \& Smith, E. A. (2020). Parenting practice, leisure experience, and substance use among South African adolescents. Journal of leisure research, 51(1), 36-55. https://doi.org/10.1080/00222216.2019.1620144

Yoon, H., Lee, W. S., Kim, K. B., \& Moon, J. (2020). Effects of leisure participation on life satisfaction in older Korean adults: A panel analysis. International journal of environmental research and public health, 17(12), 4402. https://doi.org/10.3390/ijerph17124402

Zervou, F., Stavrou, N. A., Koehn, S., Zounhia, K., \& Psychountaki, M. (2017). Motives for exercise participation: The role of individual and psychological characteristics. Cogent psychology, 4(1), 1345141. https://doi.org/10.1080/23311908.2017.1345141

Zhang, S. X., Wang, Y., Rauch, A., \& Wei, F. (2020). Unprecedented disruption of lives and work: Health, distress and life satisfaction of working adults in China one month into the COVID-19 outbreak. Psychiatry research, 288, 112958. https://doi.org/10.1016/j.psychres.2020.112958

\section{Copyrights}

Copyright for this article is retained by the author(s), with first publication rights granted to the journal.

This is an open-access article distributed under the terms and conditions of the Creative Commons Attribution license (http://creativecommons.org/licenses/by/4.0/). 